\title{
Role of Stress Management on the Relationship between Information Overload Syndrome and Performance of Universiti Utara Malaysia
}

\author{
Saralah Devi Mariamdaran ${ }^{1, *}$, Arsaythamby A/L Veloo ${ }^{2}$ \\ ${ }^{1}$ School of Applied Psychology, Policy and Social Work, College of Arts and Sciences, Universiti Utara Malaysia, Malaysia \\ ${ }^{2}$ School of Education and Modern Languages, College of Arts and Sciences, Universiti Utara Malaysia, Malaysia
}

Copyright $\subseteq 2017$ by authors, all rights reserved. Authors agree that this article remains permanently open access under the terms of the Creative Commons Attribution License 4.0 International License

\begin{abstract}
Research has identified the moderating role of stress management on the relationship between information overload syndrome and performance (IOS\&P) of university students. Observation conducted due to Information Technologies usages. Research has become relatively easy as all the materials are readily available, but at the same time too much information acts as a noise and students feel problematic in choosing the right information which causes stress and affects students' performance. The IOS\&P framework has been tested with the help of primary data collected from the students of Universiti Utara Malaysia. The findings of the study revealed that information overload syndrome has a negative impact over the performance of students. Furthermore, the addition of moderating variable i.e. stress management converts the negative impact into positive impact and has increased the value of explained variation. Thus, the overall framework has been approved and the study highlighted that there is a significant moderating role of stress management over the relationship between information overload syndrome and students performance.
\end{abstract}

Keywords Psychology, Information Overload Syndrome, Postgraduates, Universiti Utara Malaysia

\section{Introduction}

Performance of students is derived when there is no extra load of information over the students, which causes counter productivity because of information overload syndrome. In the current society and modern era the word overload is not new. Students also get information through the networking like blogs or through emails and other sources where people are connected to each other. Then comes the phase of social media, in which students share ideas and feelings between communities [1].

Information overload means the level of difficulty that a student faces when the student fails to handle excessive information. Every student has his/her own level of understanding. The level of understanding of any student can be checked through various tests. One can also check the understanding and comprehension level by assigning the task to students. When the teachers are aware of the capabilities of their students, they can get more productivity from their students [2].

There has been an increase in number of studies on information overload syndrome. The concept of information overload has begun since $20^{\text {th }}$ century. The issue of information overload has increased with the passage of time [3]. Though currently the students can see the work overload in their circle and they can see it in other fields as well. But this is a major concern for the students as they have a lot of load regarding assignments and projects [4]. To prepare the assignment students are exposed to internet all the time. Due to these issues the performance of students and especially the psychology of students are adversely suffering.

In simple language, information overload is used to convey a notion and receive too much information in minimum time. Too much information and communication may also lead to problems especially for the university students. Within the student community it can be seen that this term is now very common and has been increasing vastly. The information overloads, influences the performance of students and especially those who generally lack skills to manage information overload [5]. If the students face cognitive strain along with high level of stress then the satisfaction level will decreases, which will cause stress. Students will study more efficiently if they are not stressed because of information overload syndrome.

Stress is an element which occurs when the student is not satisfied and has a lot of work load regarding his studies. Students will not be able to make good decision under high 
level of stress which will cause poor performance [6]. Students and especially the university students will not be able to make decisions in this state because they have to do research work which further enhances information overload.

Many researchers have said that information overload is a construct, in which students have lots of information in one field but they overlap and one cannot make the particular decision. It also means that the information that students possess is less and the amount of information required is more. These are the things that are included in the work overload especially while preparing projects and research work. According to Klapp (1986) the large amount of information feels like noise. This happens when students have excess information. The students have to deal with the large number of subjects, which is a regular feature. They have to study all the courses together in a very short time. Thus, the information is not transferred in an effective way. The students will suffer both of the efficiency and effectiveness. Information overload can also be said when one has a large number of information and one doesn't know how to process that data and what to do with the same data [7]. In the current era communication devices and applications have also overloaded the supply of the information [8].The aim of delivering the vision is affected highly and these are the things that cause stress among academicians in the society [9].

If one looks back at the last 50 years the information has gone so far and the concept has been readily available for the students [10]. But currently information can be found around the globe [11]. That's where the problem arises in this case one cannot judge the abilities of the person and cannot check the capacity of that person because everything is now readily available. They need to go through the figures if they have a lot of them. So it creates a confusion and makes difficulties among the students and researchers on which one to select and which one to reject. Therefore, along with the ease of information that is available, there are many problems too and these are the things that were claimed by the researchers and the university students. These people have claimed that with the density of information one can simply increase his stress level and will not be able to get satisfied [12].

Over the past few years the machines have taken the place of people and now the people are not as much seen in any field as machines are [13]. In some fields the information can be the tool of making the right decisions [14]. With the amount of information now it's very difficult to make the decisions and such elements have started reducing the power of decision making. Thus, it would be right to say that information has positive as well as negative impacts. The researchers have made this specifically for the management side but such things also apply in academics and especially for the university students [15]. This situation cannot last long and students start losing control over their studies. In the current era everyone can see the great flood of the information [16].

Student can find the information in an easy way which ultimately has a negative effect in the form of overload. New information is spreading day by day through an email from the different departments. With the new information and knowledge one is capable to produce new things. These things may be very useful and especially all the happenings in the last decade. The volume of the knowledge is increasing and it will grow every day. The problem of the work overload is occurring day by day and the syndrome has led us to the crucial challenges [17]. It has created the problems like the psychology and more problems that are related to the human beings. Such issues need to be resolved with the optimal solution to solve such conflicts between work life and information.

Now educational institutes are at the beginning of the problem of overload. These issues were not taken seriously as students were not able to feel them. But now the problem can be clearly observed. A major decline in the admission in the psychological department has been seen, which is due to declining trend among the students because of burnout [18]. The latest statistics of Social Sciences department of University Utara Malaysia have shown the worst trends.

Table 1. UUM CAS student registration

\begin{tabular}{|c|c|c|c|c|c|c|}
\hline Program / Year & 2010 & 2011 & 2012 & 2013 & 2014 & 2015 \\
\hline $\mathrm{PhD}$ & 142 & 152 & 151 & 183 & 151 & 144 \\
\hline Sarjana & 660 & 668 & 783 & 841 & 736 & 618 \\
\hline Total & 802 & 820 & 934 & 1024 & 887 & 762 \\
\hline
\end{tabular}

The research has observed that there are certain factors that are creating problems which are causing decline of student's enrolment in the higher education. The major reason behind this decline is information overload. In the modern era one needs to reduce the effect of overload. Therefore, this research has been conducted with the aspect of the organizations as well as the universities. So academicians are mainly included in this study as respondents. In this scenario they are overloaded with the information and it is difficult for the university students to absorb the overload information in the hectic routine, as the university students are given the heavy task of creating knowledge by which they cannot work effectively and efficiently [19].

Therefore, the study is being conducted to find the impact of information overload that is increasing and creating syndrome among students. With this focus the study is being conducted among university students. The purpose of this study is to provide the outline that why such problems are accruing and what is the way to cure them. These things are happening in the current situation. The purpose of this study is to investigate the past studies that are related to the information overload and several controversies have been observed leaving the issue inconclusive. According to the researchers, more analysis should be provided as the past findings are neither sufficient nor conclusive [20].

To make the conclusion or a positive image of the scenario this study is being conducted among the students of northern 
university of Malaysia. Therefore, this study is being conducted to provide meaningful findings for the academic sector especially the university students [21].

As the current scenario needs to do more research in this matter and the findings of this study are expected to provide the summary that what are the major factors that have impacts, as in the past researches it has been observed that the findings are not clearly stated as it should be and it is provided in the very short form. Thus, there is a dire need to conduct this study to provide the proper solutions for the issues discussed above.

\subsection{Research Question}

These are the questions that are properly stated and are according to the problem statement. These research questions are needed to be answered with the help of this study.

1. What is the relationship between information overload syndrome and performance of university students?

2. What is the moderating effect of stress management over the relationship between information and communication overload syndrome?

\subsection{Research Objectives}

The objectives of the study are as follows:

1. To find the impact of information overload syndrome over performance of university students.

2. To find the moderating role of stress management over the relationship between information overload syndrome and performance of university students.

\subsection{Research Hypotheses}

H1: There is a significant relation between information overload syndrome and performance of university students

$\mathrm{H} 2$ : Stress management moderates the relationship between information overload syndrome and performance of university students.

\section{Literature Review}

The concept that has been discussed and included in the current study is performance of students at University Utara Malaysia. The performance of university students is continuously deteriorating. The main reason behind this decline in performance of the university students is information overload syndrome. Another factor which is adversely affected by information overload is stress. The problem of stress is related with the information overload syndrome and is affecting the performance of university students. The stress level will certainly increase with the information level. [22]. If proper stress management is done, it will have a positive impact over the performance of university students.

\subsection{Performance of the University Students}

There is no standard definition for evaluating the performance of students. The standard approach focuses on achievement and curricula, how university students understand the courses and obtain their degrees or their marks. However, a more extensive definition of performance of university students deals with the competencies, skills, and attitudes that the students learn during their stay in the university.

The relationship between use of information overload syndrome and student performance in higher education is not clear, and there are contradictory results in the literature [23]. Earlier economic research has failed to provide a clear consensus concerning the effects on university students' achievement. Since student performance is mainly explained by a student's characteristics, and educational environment. Information overload syndrome may have an impact on these determinants and consequently the outcome of education. These may explain the observed differences in students' achievement [24].

The direct link between information overload syndrome and university students' performance has been the focus of extensive literature during the last two decades. Several studies have tried to explain the role. The first body of literature explored the impact of computer uses. Since the Internet revolution, there has been a shift in the literature that focuses more on the impact of online activities: use of Internet, use of educative online platforms, digital devices, use of blogs and wikis, etc. This literature shows mixed results. On one hand, some research demonstrates that there is no evidence of a key role for information overload syndrome in higher education especially regarding deterioration in the performance of university students. On the other hand, some studies show real impact of information overload syndrome on performance of university students [23].

Looking at the link between information overload syndrome and student performance seems nowadays a missing link of stress management [25]. It needs to be specified in order to meet the needs expressed by university students and to be adapted to the local context and constraints. Information overload syndrome brings widened possibilities for declining the learning processes, which can be minimized with the help of stress management.

\subsection{Information Overload}

Information overload refers to the difficulty that university students have faced in understanding an issue and taking the right decision. This lack of decision making power is because of having too much information. Information overload occurs when the amount of input information in the university student's brain exceeds its processing capacity [26]. University students usually have fairly limited cognitive processing capacity. Consequently, when information and communication overload occurs, it is likely 
that a reduction in decision quality will occur, which will consequently decline the performance of university students.

Basically Information Overload is the work that is directly related to the mind of the persons and depends on the skills and abilities of a student which are being utilized to complete their tasks. Information Overload is often used in the decision making process [27]. Information overload depends on the human behavior. If the student has a free state of mind then he will make the things right and take productive decision [28]. If the information overload cannot be managed then more negative effects may affect the performance of students. They can face problems mentally and physically [29].

\subsection{Impact of Information Overload Syndrome on the Performance of University Students}

The major effect of information overload syndrome includes the loss of productive time which may have been used on some other work if the mind of the student is not deviated. Information overload syndrome also reduces mental capacity of the university students. Information overload syndrome significantly affects the quality of thinking time because of deviated mind. The thinking about the productive things is deviated and the thinking time increases. Information overload syndrome not only deviates the mind but also affects the communication process. Information overload syndrome adversely affects the work planning. University students require more time to plan their work because of deviated minds. All these things collectively affects the quality of life because the available time is spent more on non-productive activities and the university students get less time for sleeping or other healthy activities [30]. Especially the university students that are doing their research work, it is interesting to note that when making complex assignments, university students may feel the need to have more information, and therefore, search massive amount of data from the information which further confuses them [31]. This consequently acts, as having too much information is the same as not having enough required information to perform the specific task. Information overload syndrome also interferes learning and creative problem solving and prolongs the thinking process and problem solving. This affect usually cause a decline in the ability of university students to solve new problems creatively.

\subsection{Moderating Role of Stress Management}

In higher education the importance of information technologies cannot be ignored. The information technologies are of great importance but all the university students need to manage the things in an effective way which is possible through effective stress management. The only thing is that if the information is growing then that will lead to stress and that can also lead towards psychological problems. These psychological problems can indirectly affect the performance of university students. As the information comes from bulk and in huge amounts, it can create the poor performance. However, if the university students can manage the amount of stress and time can be managed on these bases, the performance of university students can be increased [32].

\subsection{Theoretical Framework}

This section includes the investigation about information that can cause overload but needed in the time, and is also used to reduce stress among the students in Malaysian context. Therefore, we would like to show the theoretical frame work and they are based on three variables that explain the system in a very easy way. We have used the term, Information overload, Stress management, and we have used the term performance by which we have shown the theoretical frame work and for proper frame one needs to see figure 1 that is shown below:

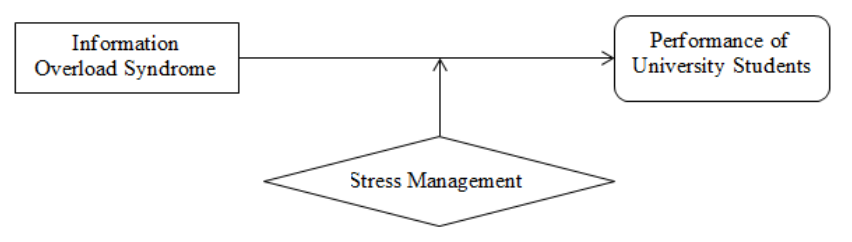

Figure 1. Conceptual Research Model linking information overload, stress management and performance of University Students

In the above mentioned proposed framework the researcher has tried to show the basic linkage between independent variable. That is information overload syndrome and the dependent variable which is performance of university students. The framework shows that information overload syndrome adversely affects performance of the university students. Poor performance is a major cause behind stress [33]. Stress kills the productive time, therefore, on the basis of the reviewed literature the argument is that stress management can moderate the relationship between information overload syndrome and performance of university students.

\section{Methodology}

The methodology section covers hypothesis development, research design, population of the study, sample size and sampling frame of the study, instruments that are used for data collection, strategy, and procedures for analyzing the data. It also explains the methods and techniques that have been used for data collection and analysis. These include location, time and the unit of analysis as well as the sampling technique and the size of the sample to be used.

\subsection{Hypothesis Development}

On the basis of above proposed framework the following 
hypotheses have been drawn:

$\mathrm{H}_{\mathrm{a}} 1$ : Information overload syndrome affects the performance of university students.

$\mathrm{H}_{\mathrm{a}} 2$ : Stress management moderates the relationship between information overload syndrome and performance of university students.

\subsection{Research Design}

Research design refers to the outline for the collection and analysis of data. Research design is a way of gathering and analyzing data to arrive at a solution. This study follows a quantitative methodology. Quantitative data analysis is a measurement where numbers are used to represent the phenomenon being studied [34]. This study adopted a survey research design [35]. The basic reason behind using primary data is that the secondary data may not be appropriate to fulfill the given situation [36]. Therefore, primary research has been conducted by gathering data regarding performance of the university students on the basis of perception of the university students regarding information overload syndrome, stress, and performance of students. In this current study the researcher used a sample from university Utara Malaysia for the collection of data.

Longitudinal study is conducted to find the impact of time or to observe a situation over a longer period of time [37]. In this research data were collected at a point in time.

Unit of analysis may be a person, an organization or a group. In this study the unit of analysis was the students of last semester studying at University Utara Malaysia.

In order to measure a variable in quantitative study, the researcher uses close ended questions; in order to measure the items the best way is to use a Likert scale. In this study different number of items has been used to measure the variables using five point Likert scale [38]. Five point Likert scale is used because both the five and seven Likert Scale are used to measure behaviors. However five is preferred because it reduces the chances of error.

For the data collection a questionnaire has been adapted with a great care. It was kept in mind that the questionnaire must be in proper form. The items used in the questionnaire have been linked with the variables that have been used in the research model. It has also been kept in mind that the questionnaire used should be in accordance with the conceptual definition of the variables and explain all the variables in a good and coherent way.

Another important issue is related to reliability and validity of the instrument. The term reliability refers to the reliability of the instrument to measure exactly what it is supposed to measure. The term validity refers to the validity of the results regarding generalization of the findings of the study [39]. In this study to find the reliability of the instruments Cronbach's alpha is used. Furthermore, for facing validity of the instrument the questionnaire was adopted from the instruments which are well established for measuring the variables.

Appropriate sample size represents the quality of research. The number of sample is dependent over the size of the population. For calculating the sample size the table given by Zikmund is used [36].

The adopted questionnaire was used to collect the data from the students of University Utara Malaysia. The university students of undergraduate level are selected for collecting the data. The questionnaire was distributed among the university students. The university students were given a time of two weeks to fill out the questionnaires. This time was allotted to them so that they can answer the questionnaires without any hurry and without any pressure.

\subsection{Data Analysis}

All the data has been tabulated in SPSS 22 for measuring descriptive and reliability. After ensuring that the instrument is reliable and there are no errors in descriptive analysis and there is no difference in early and late response, PLS-3 was used for structural equation modeling [37]. PLS-SEM is considered as the best for developing a theory and model testing. The results of the direct effects and moderation effects are mentioned below:

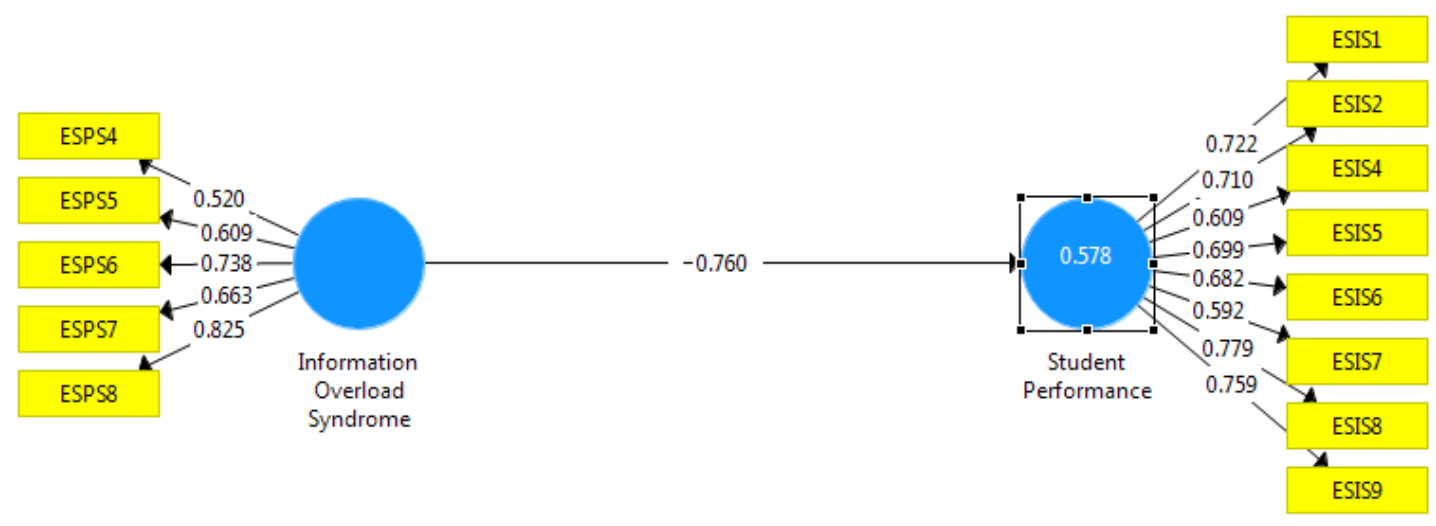

Figure 2. PLS Algorithms 
Figure 2 shows the relationship between information overload syndrome and student performance. The results show that there is a negative impact of information overload syndrome over student performance. The calculated value of r square shows that $57.8 \%$ performance of the students is explained by the information overload syndrome. In the next step boot strapping has been conducted to find the significance of the relationship.

In the figure 3 boot strapping results have been shown which shows that there is a significant relationship between information overload syndrome and student performance.

The table mentioned below shows the $t$ values and $p$ values which show that information overload syndrome significantly effects student performance.

After identifying that information overload syndrome has a negative impact over student performance, therefore, in the framework a moderating variable stress management has been introduced. The results of the moderating effects are mentioned in the diagram below.

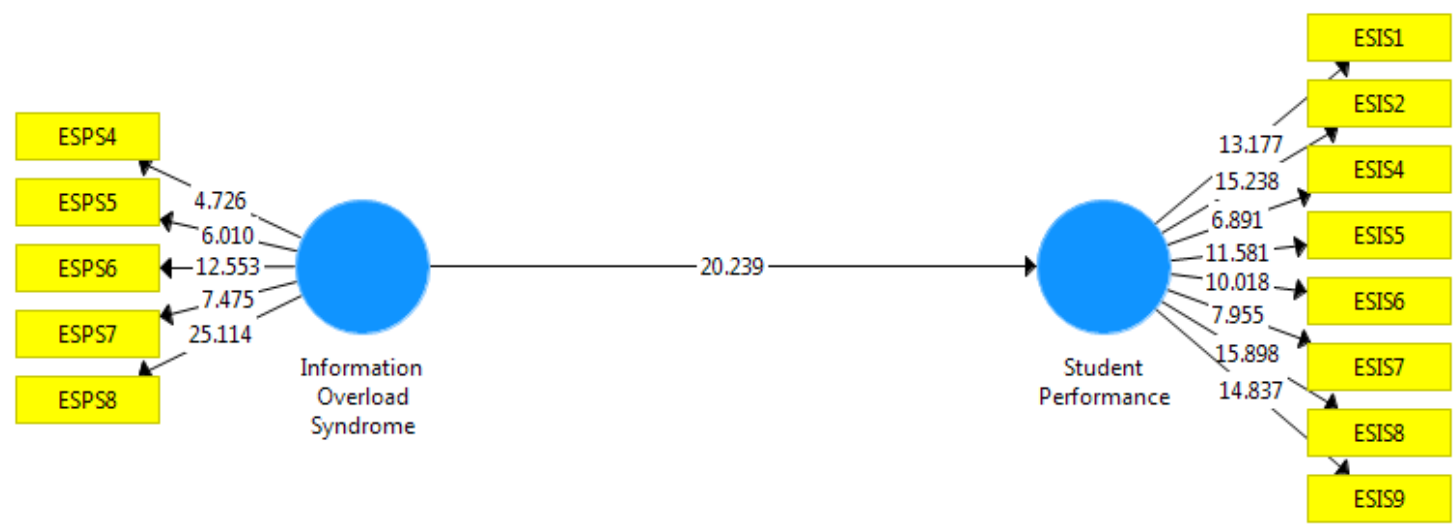

Figure 3. PLS Bootstrapping

Table 2. Path Coefficients

\begin{tabular}{|c|c|c|c|}
\hline Relationships & Path Coefficients & T statistics & P Value \\
\hline Information Overload Syndrome - > Student Performance & -0.760 & 20.239 & 0.00 \\
\hline
\end{tabular}

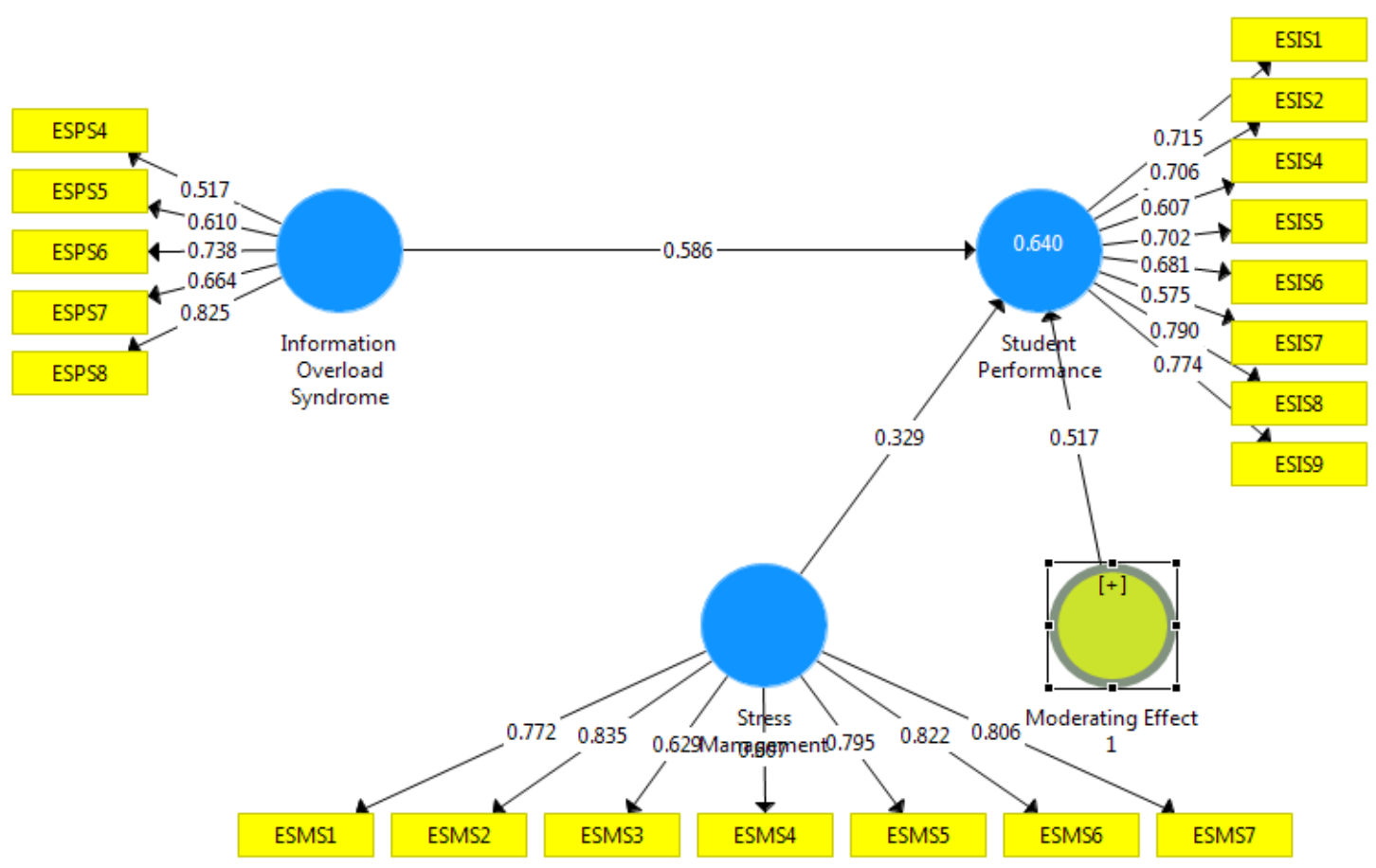

Figure 4. PLS Algorithms Moderation 


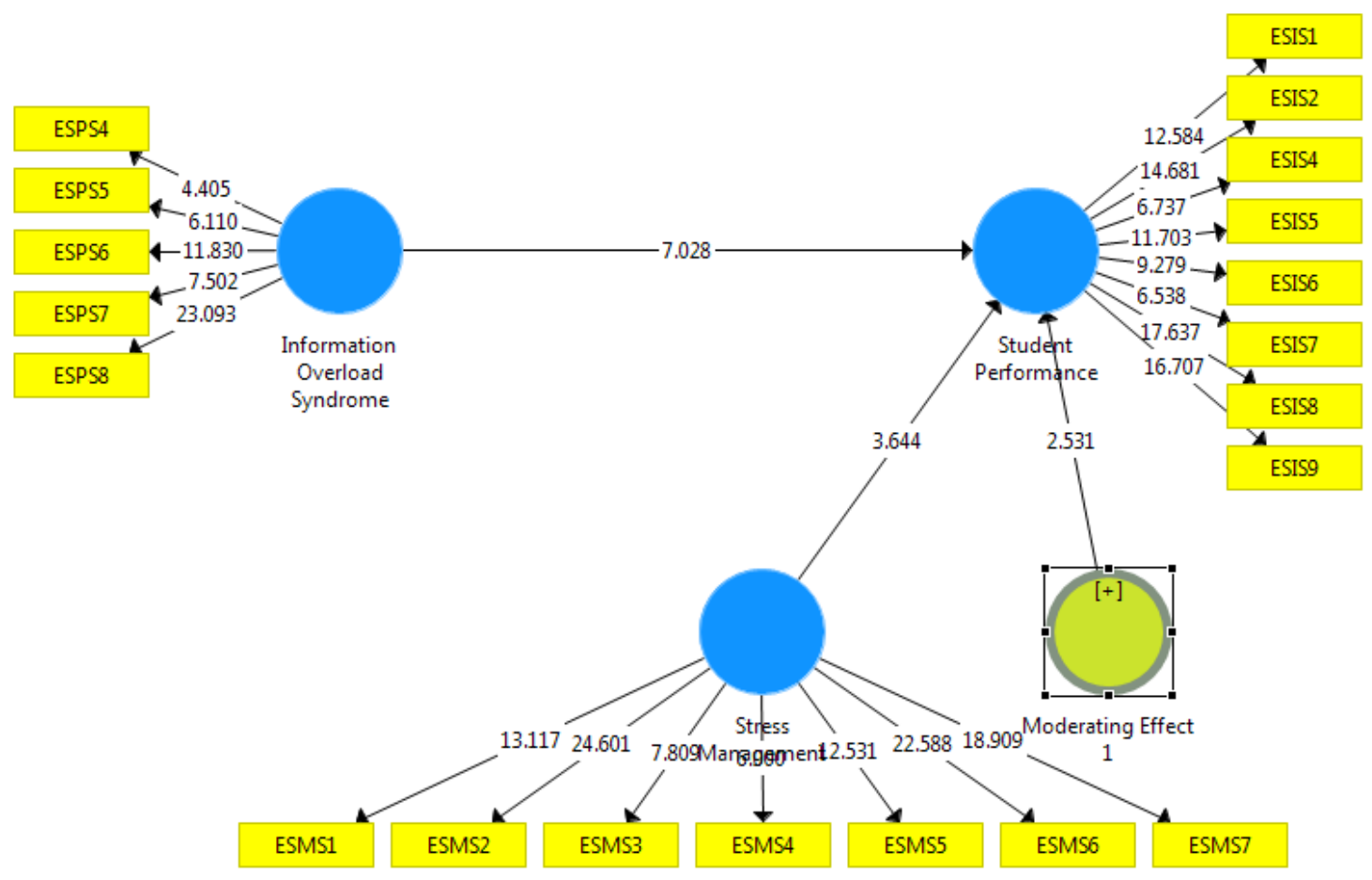

Figure 5. PLS Bootstrapping Moderation

Table 3. Path Coefficients

\begin{tabular}{|c|c|c|c|}
\hline Relationships & Path Coefficients & T Statistics & P Values \\
\hline Information Overload Syndrome - > Student Performance & 0.586 & 7.028 & 0.000 \\
\hline $\begin{array}{c}\text { Information Overload Syndrome * Stress Management- > } \\
\text { Student Performance }\end{array}$ & 0.517 & 2.531 & 0.000 \\
\hline
\end{tabular}

The path coefficients shows that that the beta value calculated for moderating effect is 0.517 , furthermore, the value of $r$ square has been increased to $64 \%$ which shows that the moderating variable has a significant impact. Furthermore, a noteworthy concept is that the negative impact of information overload syndrome has been converted to positive, which shows the impact and importance of moderating variable. In the next step boot strapping has been conducted to calculate the significance of the variable.

The above mentioned diagram shows that the results of moderating variable are significant. The moderating variable has been introduced and is shown as significant which can be observed in table 3 .

In simple words the proposed framework has been supported by the results that have been calculated with the help of primary data collected from the students of University Utara Malaysia.

\section{Conclusions}

The findings of the study highlighted that the human learning capacity can be enhanced by managing stress which is caused by information overload syndrome. Reasonable information overload is not necessarily unhelpful to most tasks. If stress is properly managed then the same information overload can be used to enhance performance of students. In certain context, information overload will certainly decrease student performance. If stress is managed properly the performance of students can be enhanced. Findings of the current study offer the basis for new framework to understand the information overload phenomenon. This research provides findings based on data collected from a relatively small sample. Thus, a suggestion for future research is to increase the size of the sample and compares them with diversified fields.

\section{REFERENCES}

[1] DeAndrea, C., D., Nicole B. Ellison, Robert LaRose, Charles Steinfield, \& Fiore, A. (2012). Serious social media: On the use of social media for improving students' adjustment to college. The Internet and higher education, 15(1), 15-23.

[2] Toffler, A. (2013). Revolutionary wealth. New Perspectives Quarterly, 30(4), 122-130.

[3] Groes, \& Sebastian. (2016). Information overload in literature. 
Textual Practice, 1-28.

[4] Csikszentmihalyi, Mihaly, \& Robinson, R. E. (2014). Culture, time, and the development of talent. The Systems Model of Creativity. Springer Netherlands, 27-46.

[5] Ruiz-Gallardo, José-Reyes, José L. González-Geraldo, \& Castaño, S. (2016). What are our students doing? Workload, time allocation and time management in PBL instruction. A case study in Science Education. Teaching and Teacher Education, 51-62.

[6] Larcombe, Wendy, Letty Tumbaga, Ian Malkin, Penelope Nicholson, \& Tokatlidis, O. (2013). Does an improved experience of law school protect students against depression, anxiety and stress? An empirical study of wellbeing and the law school experience of LLB and JD students. Sydney Law Review, 35(2).

[7] English, Mary C., \& Kitsantas, A. (2013). Supporting student self-regulated learning in problem-and project-based learning . Interdisciplinary journal of problem-based learning, 7(2), 6 .

[8] Joseph F. Hair, J., Hult, G. T., Ringle, C., \& Sarstedt, M. (2013). A Primer on Partial Least Squares Structural Equation Modeling (PLS-SEM). SAGE Publications.

[9] Abbott, \& Andrew. (2014). The problem of excess. Sociological Theory, 32(1), 1-26.

[10] Pineteh, \& Ernest. (2012). Using virtual interactions to enhance the teaching of communication skills to information technology students. British Journal of Educational Technology, 43(1), 85-96.

[11] Kaplan, A. M. (2012). If you love something, let it go mobile: Mobile marketing and mobile social media $4 \times 4$. Business horizons, 55(2), 129-139.

[12] Twenge, \& M, J. (2013). Overwhelming Evidence for Generation Me A Reply to Arnett . Emerging Adulthood 1, 21-26.

[13] Compagni, Amelia, Valentina Mele, \& Ravasi, D. (2015). How early implementations influence later adoptions of innovation: social positioning and skill reproduction in the diffusion of robotic surgery. Academy of Management Journal, $58(1), 242-27$.

[14] Bono, Joyce E., Theresa M. Glomb, Winny Shen, Eugene Kim, \& Koch, A. J. (2013). Building positive resources: Effects of positive events and positive reflection on work stress and health." Academy of Management Journal. 56(6), 1601-1627.

[15] DomíNguez, AdriáN, Joseba Saenz-De-Navarrete, Luis De-Marcos, Luis FernáNdez-Sanz, Carmen PagéS, \& MartíNez-Herrálz, J.-J. (2013). Gamifying learning experiences: Practical implications and outcomes. Computers \& Education, 63, 380-392.

[16] Stark, \& John. (2015). Product lifecycle management. In Product Lifecycle Management. Springer International Publishing, 1-29.

[17] Carrigan, M. (2016). The fragile movements of late modernity. In Morphogenesis and the Crisis of Normativity, 191-215.

[18] Schoenfeld-Tacher, Regina M., Lori R. Kogan, Beatrice Meyer-Parsons, Kenneth D. Royal, \& Shaw, J. R. (2015). Educational Research Report: Changes in Students' Levels of Empathy during the Didactic Portion of a Veterinary Program.
Journal of veterinary medical education, 42(3), 194-205.

[19] Davison, M, R., Ou, C. X., \& Martinsons, M. G. (2013). Information technology to support informal knowledge sharing. Information Systems Journal, 23(1), 89-109.

[20] Garvey, W. D. (2014). Communication: the essence of science: facilitating information exchange among librarians, scientists, engineers and students. Elsevier.

[21] Mark, George, \& Smith, A. P. (2012). Effects of occupational stress, job characteristics, coping, and attributional style on the mental health and job satisfaction of university employees. Anxiety, Stress \& Coping, 25(1), 63-78.

[22] Webster, \& Frank. (2014). Theories of the information society. Routledge.

[23] Cho, Jaehee, \& Lee, a. S. (2016). International Research International Students' Proactive Behaviors in the United States: Effects of Information-Seeking Behaviors on School Life. Journal of College Student Development, 590-603.

[24] Kuh, G. D., Timothy Reese Cain, Pat Hutchings, \& Kinzie, J. (2014). Using evidence of student learning to improve higher education. John Wiley \& Sons.

[25] Bartholomew, \& P, C. (2013). Time: An Empirical Analysis of Law Student Time Management Deficiencies. University of Cincinnati Law Review, 81(3).

[26] Gouws, Rufus H., \& Tarp, S. (2016). Information overload and data overload in lexicography. International Journal of Lexicography, 1-30.

[27] Adamson, Colin, Chris Gennaro, George Kinchen, Joshua Koehler, Peter Liu, ... Zhang, J. (2014). Adamson, Colin, Chris Gennaro, George Kinchen, Joshua Koehler, Peter Liu, Derek May-West, and Jason Zhang. Reducing Electronic Information Overload.

[28] Ahn, \& J, M. (2012). Effective Public Policy Delivery System in the Age of Information Overload-The Role of Imagery on Citizen Perception and Compliance of Public Policy. The Korean Social Science Journal, 39(1), 1-17.

[29] Harish, HG Jeya, R. Krishna Kumar, \& Raja, B. W. (2013). Bringing ICT to Teach Science Education for Students With Learning Difficulties. i-Manager's Journal on School Educational Technology, 8(4), 1-15.

[30] Zhang, Shuwei, Ling Zhao, Yaobin Lu, \& Yang, J. (2016). Do you get tired of socializing? An empirical explanation of discontinuous usage behaviour in social network services. Information \& Management .

[31] Anderson, D. M. (2014). Introduction. In Leveraging. Springer International Publishing, 3-34.

[32] Kim, BeomCheol Peter, Suzanne K. Murrmann, \& Lee, G. (n.d.). Moderating effects of gender and organizational level between role stress and job satisfaction among hotel employees. International Journal of Hospitality Management, 28(4), 612-619.

[33] Hystad, Sigurd W., Jarle Eid, Jon C. Laberg, Bjørn H. Johnsen, \& Bartone, P. T. (2009). Academic stress and health: Exploring the moderating role of personality hardiness. Scandinavian journal of educational research, 53(5), 421-429.

[34] Sekaran, U. (2007). Research Methods for Business: A Skill 
Building Approach. New York: John Wiley \& Sons, Inc.

[35] Zikmund, W., Babin, B., Carr, J., \& Griffin, M. (2012) Business Research Methods. Masson: Cengage Learning.

[36] Zikmund, W. G. (2007). Business Research Methods. New York: McGraw Hills.

[37] Hair, J. F., Sarstedt, M., Ringle, C. M., \& Mena, J. A. (2012). An assessment of the use of partial least squares structural equation modeling in marketing research. Journal of the Academy of Marketing Science, 40(3), 414-433. doi:10.1007/s11747-011-0261-6

[38] Hair, J. F., Ringle, C. M., \& Sarstedt, M. (2013). Editorial-partial least squares structural equation modeling: Rigorous applications, better results and higher acceptance. Long Range Planning, 46(1), 1-12.

[39] Lowry, P. B., \& Gaskin, J. (2014). Partial Least Squares (PLS) Structural Equation Modeling (SEM) for building and testing behavioral causal theory: When to choose it and how to use it. IEEE Transactions on Professional Communication, 57(2), 123-146. doi:10.1109/TPC.2014.2312452 